\title{
A Study on the Influence of Job Stress in Organisational Factors
}

\author{
Abhijith Jacob $^{\# 1}$, Mahesh Rengaraj ${ }^{\# 2}$ \\ ${ }^{\# 1}$ P.G. Scholar, ${ }^{\# 2}$ Associate Professor \\ Department of Mechanical Engineering, M G University \\ SCMS School of Engineering and Technology, \\ Karukutty, Ernakulam, India
}

\begin{abstract}
Today, occupational accidents are considered among the potential threats because of their serious humanitarian, economic, social, and environmental consequences. Occupational accidents and injuries are the third cause of mortality in world. In addition, the economic and environmental damages because of the occupational accidents are catastrophic too. According to International Labor Organization (ILO) report in 1999 the number of fatal accidents was 335000. Though the registered number of accidents cannot be a faultless account of all the accidents happened, but in 2000 , about 12000 work related accidents have been registered by the Department of Social Security. Calculations indicated that approximately 345000 fatal occupational accidents occurred in 1998 and that over 260 million occupational accidents causing at least 3 days absence happened in the same year. This work aims to study the relation of occupational stress of workers and the accidents in a rice milling industry. The data was collected using questionnaire. The questionnaire contained 30 questions to measure the perceptions of the employees about the management practices. A five point likert scale was used. This was prepared based on review of related literature .The contents of this draft questionnaire were discussed with senior professional in the industry. Data was analyzed using IBM SPSS Statistics 20 software. Descriptive statistics and correlations of the studied variables were first analyzed. Confirmatory factor analysis was used to verify the reliability. Regression analysis was conducted to test the goodness of fit of the various models.
\end{abstract}

Keywords - industrial safety, occupational stress, accidents, factor analysis

\section{INTRODUCTION}

Today, occupational accidents are considered among the potential threats because of their serious humanitarian, economic, social, and environmental consequences. Occupational accidents and injuries are the third cause of mortality in world and the second one in Iran [5]. In addition, the economic and environmental damages of occupational accidents are catastrophic too [7].

II. According to International Labor Organization (ILO) report in 1999 the average estimated fatal occupational accident rate was 140/100 000 workers and the number of fatal accidents was 335000 [9]. Though the registered number of accidents in Iran cannot be a faultless account of all the accidents happened, but in 2000, about 12000 work related accidents have been registered by the Department of Social Security [9]. Calculations indicated that approximately 345000 fatal occupational accidents occurred in 1998 and that over 260 million occupational accidents causing at least 3 days absence happened in the same year [9].

III. ILO has estimated that the total costs of occupational accidents and work-related diseases are $4 \%$ of the Gross National Product (GNP) [9]. Critical incidents and accidents are caused by a combination of equipment, active and latent failures [Ref 8]. Studies reveal that human factor is the main cause of accidents [9]. Most researchers believe that unsafe behaviors are the key agent for more than $70 \%$ of occupational accidents [9].

IV. It is usually assumed that unsafe behaviors are one of the main contributors to catastrophic disasters likelihood [1]. Disastrous accidents like Chernobyl, Three Mile Island and Bhopal are all examples of these kinds [4]. In addition to lack of necessary skills, inherent characteristics, incorrect beliefs, and attitudes, one of the most important causes of unsafe behaviors is high occupational stresses [7]. Job stress factors cause a fall in concentration and the ability of decision making, and an increase in absent-mindedness, poor memory, and doubtfulness in people that lead to do unsafe acts of employees [7]. Several studies have also proved that stress has played a role in $37 \%$ of the accidents $\&$ injuries in industry [1].

\section{A. Organisational study}

Organizational studies encompass the study of organizations from multiple viewpoints, methods, and levels of analysis. Whenever people interact in organizations, many factors come into play. Modern organizational studies attempt to understand and model these factors. In the past, the inspection of major hazard plant has typically focussed on the technical aspects of safety. In recent years the emphasis has shifted towards organisational and management factors, with concepts such as "safety culture" and "safety management systems" receiving increasing attention. This can in part be attributed to inquiries into major accidents over the past decade having identified weaknesses in organisations as a primary underlying cause (Linda et al., 1995). In their study Simard et al., (1995) estimated the influence of various micro-macro organisational factors on the propensity of workgroups to take safety initiatives. Later 
studies showed that organizational and social factors do influence safety performance (e.g., Cox and Flin, 1998; Donald and Canter, 1994; Glendon and Stanton, 2000; Guldenmund, 2000; Vinodkumar and Bhasi, 2009). Even though a clear consensus is yet to evolve on the dimensions to be included in the organisational factors of industrial safety, it is widely accepted that they are good predictors of safety related outcomes (Simard et al., 1995).

\section{B. The present study}

The study was conducted in an rice milling industry in Kerala, India.

The objectives of the study are:

- To conduct a study on the occupational stress on the workers.

- To determine the organisational factors that influence industrial safety thereby the job stress in the industry using principal component factor analysis.

- To identify perceptions of employees about the organisational factors.

- To evaluate the association between perception of employees and actual safety performance in terms of injury experiences.

\section{MATERIALS AND METHOD}

\section{A. Description of case study plant}

This study was carried out at an rice milling industry located in India. The case study plant is a private sector industry in Kerala, India. There are approximately 100 employees working at 8 departments of the plant. As per the company any harm, hurt, wound or damage to the body is considered as an injury/accident. A Pareto plot was drawn for the causes of stress.

\section{B. Description of subject population}

The organisation hierarchy broadly comprises of frontline, middle line and managerial posts. Frontline employees are the workers primarily handling the shop floor activities and include designations of skilled worker and technical assistant. Officer and engineer designation comes under the middle line employees who directly monitors and controls the shop floor activities. The managerial post is entrusted with the duty of administration of particular departments. Majority of the employees are temporary workers and lacks the privileges of the permanent employees.

Among the respondents, $25 \%$ belonged to the age group of $18-30$ years, $23 \%$ belong to the age group of $31-40$ years, $30 \%$ belonged to age group of $41-50$ and $22 \%$ belonged to the age group of more than 50 and $40 \%$ of the respondents had less than 5 years experience, $23 \%$ had 5-10 years experience, $16 \%$ had 11-20 years of experience and about $21 \%$ had above 20 years of experience. In order to ensure good response rate it was decided to collect the questionnaire back immediately if possible. Thus questionnaire was distributed to employees during leisure time.

\section{Survey instrument}

From review of related literature and theory, a 30 item questionnaire covering areas of factors intrinsic to the job, relationships at work, role in the organisation, career development, organisational structure and climate and home and work interface was prepared. This was prepared based on review of related literature. The contents of this draft questionnaire were discussed with senior professional in the industry. A pilot survey was conducted on a selected sample of 10 workers to get the feedback about the clarity of the items. Those items with reliability measure less than 0.6 were dropped from the instrument [2]. After considering each item in detail, necessary changes were made by simplifying, rewording, removing and replacing some of the items. It was decided to give the questions in English as well as the local language Malayalam.

Each item was measured on a Likert scale. Likert scale is a type of response scale often used in questionnaires, and is the most widely used scale in questionnaire survey.In this study respondents were asked to give their preference on a five point Likert scale(strongly disagree, disagree, neutral, agree, strongly agree) in order to evaluate the respondents level of agreement with each item.

The questionnaire consisted of two parts. First part consisted four demographic questions about the age, sex, designation and experience. The 30 statements related to stress formed the second part. Space was provided beside each statement to mark the preference in the 5-point Likert scale. Completed questionnaires were personally collected from the participants and a total of 100 completed response sheets were received.

\section{Analyses}

The analyses were conducted as per the objectives of the study outlined in introduction. Accordingly, the analyses comprise three phases. First, factor analysis was used to factor the items and determine hidden dimensions, if any. Further, to test the differences in perception of employees among the significant demographic factors, analysis of variance was conducted. Finally, to examine the relationship between organisational factors and occupational stress, linear regression was modelled with due consideration of the significant factors obtained through earlier phases of analyses.

\section{RESULTS}

\section{A. Factor analysis}

The data collected were used to develop a factor model with varimax rotation using SPSS statistical program. The inter item correlation obtained was satisfactory. Internal consistency, Cronbach's alpha was calculated for the items, resulting in a reliability measure of 0.741 which is above the acceptable limit of 0.6 (Hair et al., 1995). The factor loading 
cut-off was fixed at 0.4.The data are fit for the factor analysis, as indicated by the Kaiser-Meyer-Olkin (KMO) measure of sampling adequacy value of 0.771 . Bartlett Test of Sphericity is also significant $\left(\mathrm{X}^{2}=550.75, \mathrm{df}=215, \mathrm{p}=\right.$ 0.000). A 4-factor model is retained from a set of combinations tested, which together explained $60.047 \%$ of the total variance.
The results of the factor analysis are presented in Table 1. The four factors identified are named as (a) organisational, (b)general, (c) individual and (d) superior co-worker. Reliability measures for individual factors range from 0.61 to 0.75 , indicating adequate internal consistency.

Table 1. Results of factor analysis showing factor name, no. of items, factor loadings, \% variance explained and Cronbach alpha

\begin{tabular}{ccccc}
\hline Factor name & Items & Factor loadings & \% variance explained & Cronbach alpha \\
\hline Organistional Factor & 9 & $0.6-0.839$ & 19.604 & 0.75 \\
General Factor & 8 & $0.573-0.679$ & 18.368 & 0.614 \\
Individual Factor & 6 & $0.627-0.830$ & 13.492 \\
$\quad$ \\
$\begin{array}{c}\text { Superior Co-worker } \\
\text { Factor }\end{array}$ & 3 & $0.691-0.737$ & 8.584 & 0.713 \\
\hline
\end{tabular}

Table 2. Results of correlation analysis

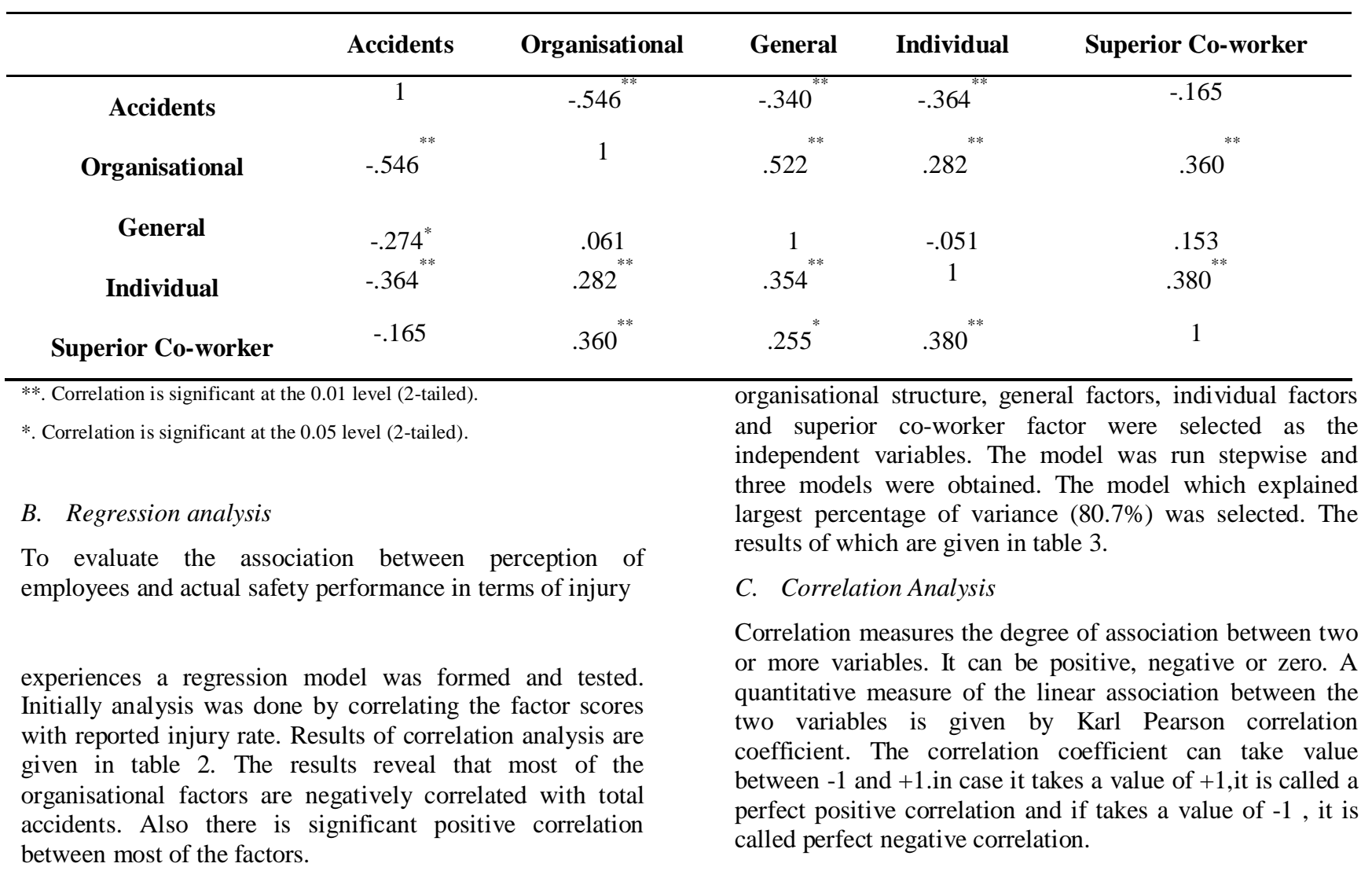

Further in the regression model self reported injuries were the dependent variable and organisational factors namely 
Table 3. Results of regression analysis

\begin{tabular}{|c|c|c|c|c|c|c|}
\hline \multicolumn{7}{|c|}{ Coefficients $^{\mathrm{a}}$} \\
\hline \multirow{2}{*}{\multicolumn{2}{|c|}{ Model }} & \multicolumn{2}{|c|}{$\begin{array}{l}\text { Unstandardized } \\
\text { Coefficients }\end{array}$} & \multirow{2}{*}{$\begin{array}{c}\text { Standardized } \\
\text { Coefficients } \\
\text { Beta } \\
\end{array}$} & \multirow[b]{2}{*}{$\mathrm{t}$} & \multirow[b]{2}{*}{ Sig. } \\
\hline & & B & $\begin{array}{l}\text { Std. } \\
\text { Error }\end{array}$ & & & \\
\hline \multirow[t]{5}{*}{1} & (Constant) & 9.449 & 1.101 & & 8.583 & .000 \\
\hline & Organisational_structure & -.130 & .029 & -.442 & -4.461 & .000 \\
\hline & general_factor & -.075 & .047 & -.159 & -1.613 & .110 \\
\hline & individual_factors & -.126 & .050 & -.230 & -2.509 & .14 \\
\hline & superior_coworker & .148 & .111 & .122 & 1.331 & .108 \\
\hline
\end{tabular}

\section{DISCUSSION AND CONCLUSIONS}

One of the key interests of this study was to determine organisational safety structure in an electrical industry. The dimensions included in the initial questionnaire preparation phase were chosen from various previous studies conducted in a variety of industries. The four factors obtained after the factor analysis were seen individually in other reports (Linda et al., 1995, Simard et al., 1995). Management commitment, (Zohar, 1980; Cox and Cheyne, 2000) is often taken as a significant factor in organisational and safety climate studies. Many of the factors are comparable with the results of other studies conducted in various industries and could be concluded that some generic factors do exist in organisational safety studies.

The relative importance of the independent variables is obtained by the absolute value of the standardized regression coefficients given in table 3 . From table 3 it is found that management structure has the significant value.

About $34.8 \%$ of the total accidents occurring due to the work stress is contributed by the organisational structure.

Most of the factors have a negative correlation with the total number of accidents. This is in tune with the findings of Donald and Canter (1994). The regression results confirm that the factors are indeed predictors of self reported accidents. Further investigation was carried out to find out the difference in perception between different groups of individuals.

One of the key interests of this study was to determine the effect of organisational structure on the stress of the workers of a rice milling industry. The dimensions included in the initial questionnaire preparation phase were chosen from various previous studies conducted in a variety of industries. An important feature of this study is its reliability and constructs validity. In this study it is revealed that all of the four management practices have good reliability suggesting that the survey items were appropriate indicators of their respective construct. It is revealed that organisational structure has more influence in the stress. The study also demonstrated that the perceptions of safety management practices influence the rate of accidents. The various practices that come under this factor are:

- Organizational policies

- Career planning and counselling

- Enrich job satisfaction of the employees.

- Social climatic change

By improvising these practices the occupational stress can be reduced to a good extent. The result of this study also highlighted the need of career planning and counselling to the workforce. The results look encouraging and promising as they posses good reliability.

\section{ACKNOWLEDGEMENTS}

The authors gratefully acknowledge the support and cooperation provided by the respondents and management of the industry studied. The authors would like to thank everyone who with their constructive comments helped to improve the quality of the paper. 


\section{REFERENCES}

[1] Donald, I., Canter, D., Employees attitudes and safety in the chemical industry. Journal of Loss Prevention in the Process Industries, 1994.

[2] Hair, J.F., Anderson, R.E., Tatham, R.L., Black, W.C., Multivariate data analysis with readings, fourth ed. PrenticeHall, New Jersey, 1995.

[3] Kothari C.R., Research Methodology Methods \& Techniques, New Age International Publishers, 2004

[4] Dr Linda J Bellamy, Bridget A Leathley, and W. Huw Gibson, 1995. Organisational Factors and Safety.

[5] H. Soori, M. Rahimi and H. Mohseni: Occupational Stress And Work Related Unintentional Injuries Among Iranian Car Manufacturing Workers

[6] Karen Belkic,MD, Cedo Savic, MD,2008 : The Occupational Stress Index-An Approach Derived From Cognitive Ergonomics

[7] M.N. Vinodkumar , M. Bhasi: Safety Climate Factors And Its Relationship With Accidents And Personal Attributes In The Chemical Industry

[8] M.N. Vinodkumar, M. Bhasi: Safety Management Practices And Safety Behaviour: Assessing Mediating Role Of Safety Knowledge And Motivation, 2010

[9] Mohammad Khandan, Shahram Vosoughi, Dr. Maryam Maghsoudipour, Iran: Evaluation of Safety Climate Factors - a Macroergonomics Approach: A Case Study

[10] Zohar, D., Safety climate in industrial organizations: theoretical and applied implications. Journal of Applied Psychology, 1980 